\title{
Nova estratégia de técnica na moldagem com casquete
}

\author{
Raulino Naves Borges¹, Bárbara Morais², Mauro de Melo³, Whaine Morais Arantes Filho4, Denise Fer-
} reira Vieira ${ }^{5}$ e Lívia Graziele Rodrigues ${ }^{6}$

${ }^{1}$ Doutor em Ciências da Saúde pela Faculdade de Medicina da Universidade Federal de Goiás. Mestre em Prótese dentária pela FO/UFG; Especialista em Desordens Temporomandibulares e dor orofacial. Cirurgiã-dentista pela FO/UFG. ${ }^{2}$ Mestre em Odontologia pela FO/UFG. Especialista em Ortodontia pela FUNORTE - SOEBRAS. ${ }^{3}$ Doutor e Mestre em Reabilitação Oral pela FOB/USP. Especialista em Prótese Dentária. ${ }^{4}$ Cirurgião-dentista pela FO/UFG. Especialista em Implantodontia pela FUNORTE - SOEBRAS. ${ }^{5}$ Cirurgiã-dentista pela FO/UFG.

Especialista em Prótese Dentária pela ABO-GO. ${ }^{6}$ Cirurgiã-dentista pela FO/UFG. Mestre em Odontologia pela FO/UFG. Especialista em Odontologia Legal pela ABO-GO.

\section{Resumo}

Para alcançar maior qualidade nas moldagens para Prótese Parcial Fixa (PPF), foi desenvolvida uma técnica precisa e de fácil aplicação. A técnica do casquete foi modificada ao criar as condições para introduzir pressão no momento de inserir o material de moldagem. Esta modificação consiste na realização de um orifício na parte superior do casquete de acrílico para moldagem, no qual o material de impressão é injetado e tem o objetivo de afastar os tecidos moles gengivais, sem necessidade do uso de fios de afastamento, que podem trazer danos ao tecido e/ou absorção de fluidos prejudiciais à saúde sistêmica de determinados pacientes. Pode-se observar que é um procedimento fácil, não traumático, econômico, rápido e preciso, tornando desnecessário o procedimento de afastamento mecânico.

Palavras-chave: Materiais para Moldagem Odontológica; Técnica de Moldagem Odontológica; Adaptação Marginal

\section{Introdução}

A confecção de Próteses Parciais Fixas (PPF) envolve diversas etapas, desde o diagnóstico até sua fixação final e acompanhamento. A fase da moldagem é definida como a realização de operações clínicas, com o objetivo de se conseguir a reprodução negativa dos preparos dentais e regiões adjacentes, por meio do uso de diversos materiais e técnicas. Para obter-se um modelo preciso e detalhado, é necessário que haja uma moldagem adequada dos dentes preparados ${ }^{16}$. A confecção de bons moldes exige tempo e trabalho do cirurgião-dentista, assim, é importante a utilização de técnicas que propiciem facilidade e agilidade de tais procedimentos, o que facilita a confecção da PPF, bem como sua precisão e adaptação ${ }^{14}$.

O preparo dentário ao nível subgengival é uma constante na clínica diária do profissional. Está associada às exigências estéticas do paciente e à saúde periodontal, já que uma gengiva inflamada não permite a obtenção de modelos adequados ${ }^{13}$.

Para que a adaptação seja perfeita, o afastamento gengival, no momento da moldagem, deve permitir que o material de moldagem seja inserido no sulco gengival e copie perfeitamente o término do preparo ${ }^{13}$. Vários fatores, como o afastamento gengival durante a moldagem, podem causar traumas ao periodonto.

Dessa forma, é imprescindível que a técnica de afastamento gengival seja adequada e proteja os tecidos gengivais ${ }^{5,6,16}$. Existem diferentes técnicas usadas para o afastamento gengival, entre elas, destacam-se os meios mecânico, químico-mecânico e cirúrgico. O afastamento mecânico é feito com casquetes, normalmente de resina acrílica autopolimerizável; no químico-mecânico, utilizam-se fios retratores embebidos em substâncias químicas, sendo que este, em alguns casos, é contra-indicado devido a presença do agente hemostático; o cirúrgico, no qual são empregadas intervenções cirúrgicas convencionais (gengivoplastia, cunha interproximal, gengivectomia, aumento de coroa clínica) e não convencional (eletrocirurgia), o qual é mais complexa e pode deixar sequelas, que podem influenciar na estética final|6,9.

Deve-se reiterar que o principal objetivo da moldagem é o sucesso do trabalho, como consequência a satisfação do paciente. Portanto, é necessário avaliar a região da boca para aplicação da técnica selecionada, o tipo de tecido periodontal a ser afastado, o material de moldagem que será empregado e a habilidade do profissional para aplicá-los ${ }^{13}$.

Sabe-se que as vantagens do uso do casquete são a facilidade do controle do processo, baixo custo, por usar um mínimo de material, rápida e não-traumática ao periodonto, além de ser confiável, segura e indolor ${ }^{6}$. Objetivo deste trabalho é apresentar e discutir uma modificação na técnica de

\section{Descrição da técnica}

A técnica está descrita em passos divididos em três fases, para melhor visualização: obtenção do casquete para moldagem, moldagem com casquete e moldagem de transferência. As figuras apresentam as fases de moldagem de dois casos clínicos de pacientes de um projeto pesquisa e extensão de Dor Orofacial e Disfunção Temporomandibular, da Faculdade de Odontologia, da Universidade Federal de Goiás (UFG), submetido ao Comitê de Ética e Pesquisa da UFG, com protocolo $n^{\circ} 140 / 03$ de 15/8/2008. Após esclarecimentos sobre a pesquisa, os pacientes assinaram um termo de consentimento livre e esclarecido, autorizando o uso das imagens para fins de publicação em veículos científicos.

\section{OBTENÇÃO DO CASQUETE PARA MOLDAGEM}

1. Use a coroa provisória para a confecção do 
casquete, utilizando o hidrocoloide irreversível como material de moldagem para sua duplicação.

2. Coloque o alginato em uma moldeira de estoque e na parte interna da coroa provisória, inserindo-a horizontalmente no alginato, de forma que apenas a face incisal/oclusal fique aparente.

3. Após a geleificação, retire a coroa provisória, obtendo um espaço negativo no material de moldagem referente à face interna da coroa provisória (Figura $1, A-B)$.

4. Preencha o negativo no alginato deixado pela coroa provisória com resina acrílica autopolimerizável.

5. Retire o casquete e faça o alívio interno e o acabamento

6. Realize na boca o reembasamento da região cervical do casquete, com resinas acrílicas especiais que sofram menores alterações. Uma porção da resina acrí- uma broca esférica em alta rotação, obtendo um orifício com o diâmetro igual ao do bico da seringa de inserção do elastômero (Figura 2).

\section{MOLDAGEM COM CASQUETE}

10. Pincele o casquete com um adesivo para adesão do material de moldagem, a mercaptana.

11. Posicione o casquete no dente preparado, proporcione e manipule a base/catalisador da mercaptana, colocando-a em uma seringa para inserção de elastômero.

12. Introduza o bico da seringa no orifício do casquete injetando o material até que extravase (Figura 4), mantendo-o em posição até a completa polimerização. O material de moldagem deve preencher o espaço entre o núcleo e o casquete e extravasar nas bordas (figura 4) copiando todo o preparo até o sulco cervical, a

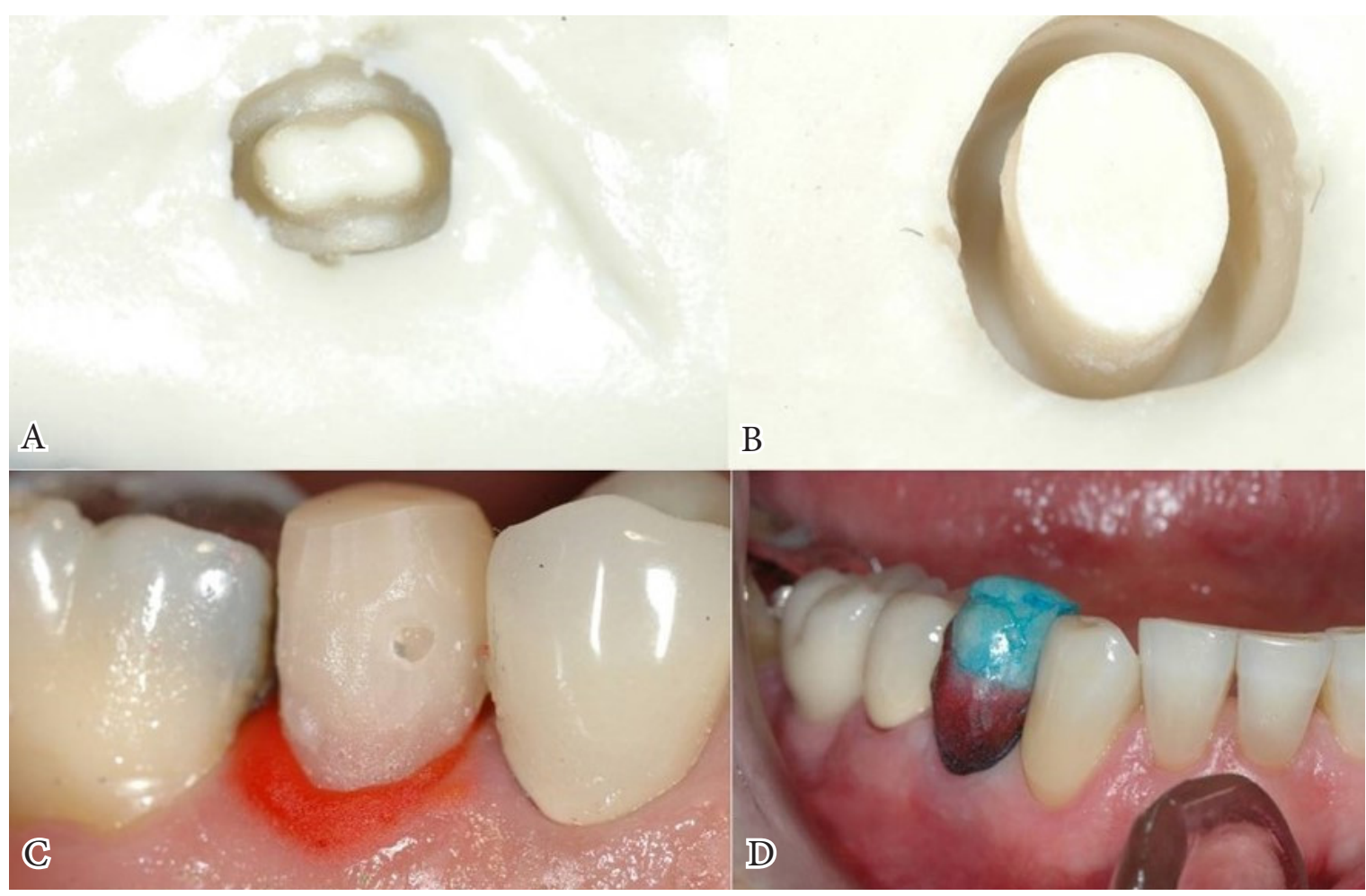

Figura 1 - (A-B) Negativo da reprodução do provisório; (C-D) Reembasamento do casquete.

lica é depositada no término do preparo e espalhada no sulco gengival, com um instrumento tipo Hollemba$c k$, em seguida o casquete é posicionado e pressionado.

7. Aguarde a polimerização para remoção e acabamento do casquete (Figura 1, C-D).

8. Se necessário, adicione resina acrílica para que o término cervical do preparo fique nitidamente copiado (reembasamento), neste local deve estar nítida a margem do preparo, conhecido vulgarmente como "saia", que será responsável pelo afastamento gengival.

9. Para a modificação da técnica, perfure a parte superior do casquete (incisal ou oclusal), com partir do princípio de que a pressão exercida pela injeção de elastômero dentro casquete empurre a gengiva marginal livre permitindo a cópia fiel (Figura 2).

\section{MOLDAGEM DE TRANSFERÊNCIA}

13. Realize a moldagem de transferência com silicona de condensação para transportar o casquete com o material de moldagem. Utilize a técnica da dupla mistura, com um material de moldagem tipo pesado e leve. Carregue a moldeira com o material pesado e o casquete e dentes vizinhos são cobertos com o material mais fluido, em seguida, leve a moldeira em posição na 
boca.

14. Completada a reação de presa do material de moldagem, remova o conjunto contendo o casquete de moldagem.

15. Confeccione o troquel de trabalho obtendo o modelo (Figura 2). casos de paciente cardiopata. Estudos mostram que a epinefrina é uma das soluções mais utilizadas4,10, o que pode causar danos cardiovasculares, quando não se conhece as condições sistêmicas de saúde dos pacientes. Em procedimentos de moldagem, quantidades potencialmente significativas de epinefrina podem ser

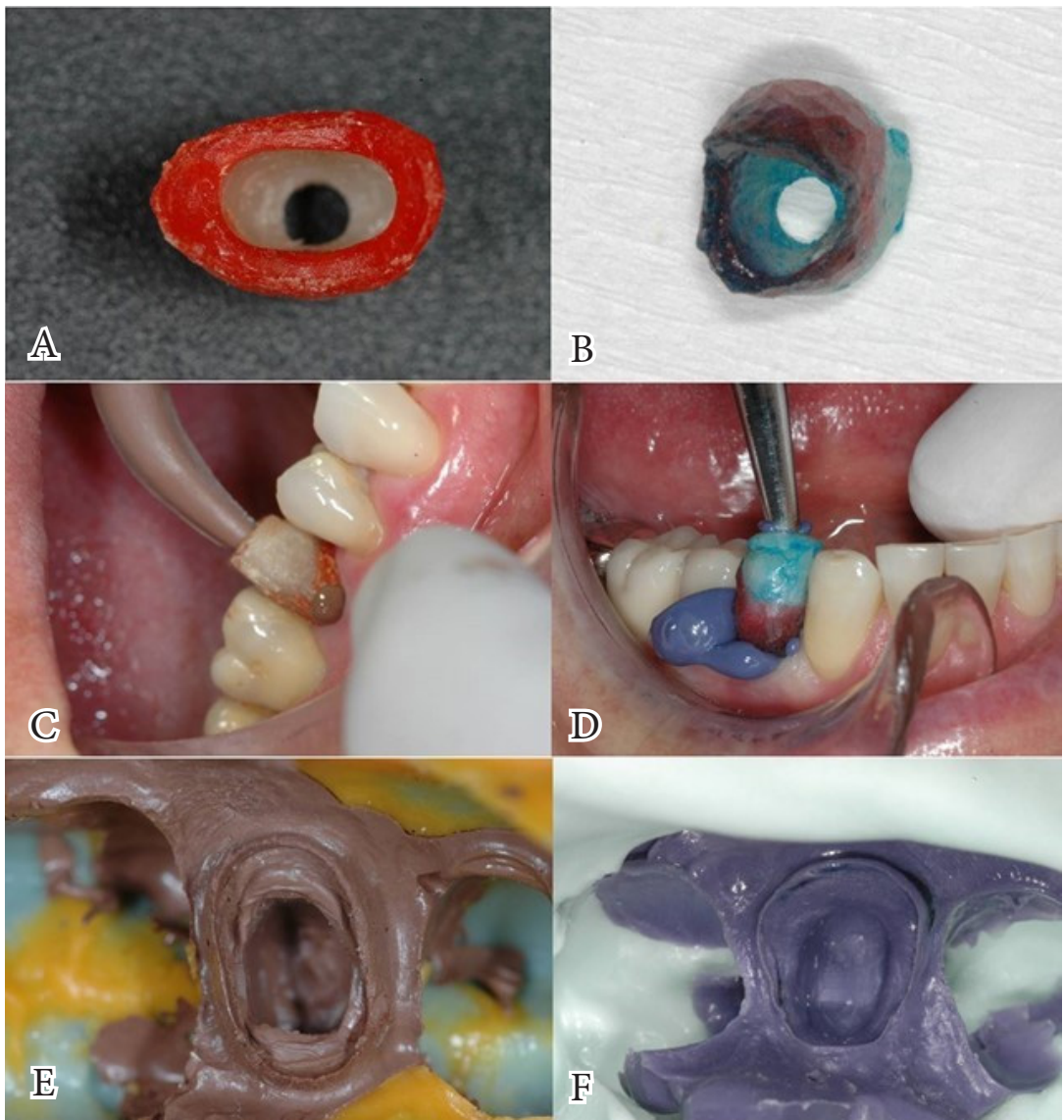

Figura 2 - (A-B) Casquete reembasado e perfurado; (C-D) Inserção do material no casquete. Observar o extravasamento do material; (E-F) Obtenção do molde com a técnica modificada de moldagem com casquete.

\section{Discussão}

A moldagem de preparos dentários para a confecção de uma restauração indireta é um procedimento muito importante, uma vez que tem forte relação com seu sucesso clínico. Todavia, é uma etapa complexa e sensível à destreza do profissional. Assim uma moldagem correta que exponha o término gengival do preparo dentário é fase essencial para a confecção de próteses fixas unitárias ou múltiplas ${ }^{12,15}$. Para uma boa adaptação, é necessário um adequado afastamento gengival que permita ao material modelador penetrar na área correspondente ao sulco gengival e assim, copiar o término cervical do preparo ${ }^{6,13}$.

Neste trabalho, uma modificação da técnica de moldagem com casquete, foi apresentada com o intuito de aliar as vantagens da moldagem com casquete convencional à injeção de material de moldagem sob pressão, sem necessitar de afastamento gengival químico-mecânico, como por exemplo, com fio afastador e substância hemostática, que são contraindicadas em absorvidas sistematicamente, a partir da solução anestésica local, secreção de epinefrina endógena em resposta ao estresse e ao presente no fio de retração ${ }^{2-5}$.

O tempo do procedimento de afastamento gengival é objeto de estudos, que buscam alternativas para redução do mesmo ${ }^{10}$. A técnica descrita no presente estudo, reduz o tempo de moldagem, pois as etapas de inserção e posterior remoção do fio de afastamento são dispensadas ${ }^{2,5,11}$. Além disso, reduz-se riscos sistêmicos e os custos inerentes a estes materiais afastadores. É importante que no momento da moldagem os tecidos gengivais estejam saudáveis e sejam bem manipulados, assim, o material deve ser inserido no dente preparado de forma cuidadosa ${ }^{7,8}$.

A técnica de casquete modificada é capaz de causar pressão no momento da inserção do material de moldagem, permitindo que este ocupe o sulco e copie de maneira fiel o preparo. Este ponto é uma evolução da técnica originalmente descrita, que simplesmente leva o casquete já carregado com material de molda- 
gem ao preparo ${ }^{14}$.

A técnica de moldagem com casquete sob pressão não é lesiva aos tecidos subjacentes ao preparo por promover o afastamento gengival com o extravasamento do material para dentro do sulco gengival, respeitando as distâncias biológicas - não invadindo o epitélio juncional. Desta forma não provoca danos irreversíveis à gengiva e não traz efeitos colaterais sistêmicos presentes após afastamento com fios ${ }^{9,15,16}$.

Entre os detalhes a serem observados nesta técnica, a manipulação adequada e correta injeção do material é fundamental para que não haja refluxo na parte superior do casquete, uma vez, que esta pressão auxiliará o afastamento dos tecidos adjacentes. Com isso, observou-se menor possibilidade de causar recessão gengival bem como danos teciduais, comuns ao uso de fios afastadores. Com esta técnica o epitélio juncional e a inserção conjuntiva são preservados ${ }^{8,11}$.

\section{Considerações finais}

Neste trabalho, foi apresentada uma variação da técnica, com resultado satisfatório. Essa variação é de fácil aplicação, rápida, de menor custo e precisa, mostrando-se como uma excelente opção de escolha na clínica diária.

\section{Referências}

1. Bassett RW, et al. An atlas of cast gold procedures. Los Angeles: Uni-Tro College Press 1964; 47-48.

2. Carvalho GL, et al. Evaluation of the Accuracy of Dual Trays Arcade. Rev ABO Nac 2004; 12:170-3.

3. Csillag M, Nyiri G, Vag J, Fazekas A. Dose-related effects of epinephrine on human gingival blood flow and crevicular fluid production used as a soaking solution for chemo-mechanical tissue retraction. J Prosthet Dent. 2007 Jan; 97(1):6-11.

4. Donovan TE, Gandara BK, Nemetz H. Review and survey of medicaments used with gingival retraction cords. J Prosthet Dent. 1985 Apr; 53(4):525-31.

5. Fazekas A, Csempesz F, Csabai Z, Vág J. Effects of pre-soaked retraction cords on the microcirculation of the human gingival margin. Oper Dent. 2002 Jul-Aug; 27(4):343-8.

6. Harnist RJD, Velmovitsky L. Why does not my impression right? Technical deficiency or material? In: Feller C, Bottino MA Atualização Clínica Odontológica: A prática na clínica geral. São Paulo: Artes Médicas. 1994

7. Harrison JD. Effect of retration materials on the gingival sulcus epithelium. J Prosth Dent 1961; 11:514-21.

8. Hummert TW, Kaiser DA. Blockout Technique for Impressions of Teeth with Increased Open Gingival Embrasures. J Prosth Dent 1999; 1:100-2.

9. Leirião FP, et al. Histological study of the periodontal structures, comparing gingival displacement by use of copper band and by cotton string, in dogs. Braz J Vet Res Anim Sci 2003; 40.
10. McCracken MS, Louis DR, Litaker MS, et. al. Impression Techniques Used for Single-Unit Crowns: Findings from the National Dental Practice-Based Research Network. J Prosthodont. 2017 Jan 11.

11. Millar B. How to Make a Good Impression (Crown and Bridge). Brit Dent J 2001; 7:402-3.

12. Rajambigai MA, Raja SR, Soundar SIJ, Kandasamy M. Quick, painless, and atraumatic gingival retraction: An overview of advanced materials. Journal of Pharmacy \& Bioallied Sciences. 2016; 8(Suppl 1):S5-S7.

13. Ribeiro JGR, Megale Costa AM, Junqueira Neto JFA, et al. Técnica alternativa para afastamento gengival e moldagem com casquete individual. Revista de Odontologia da UNESP 2005; 34(4): 179-183.

14. Shillingburg HT. Fundamentos de Prótese Fixa. $4^{\mathrm{a}}$ ed. São Paulo: Quintessence. 2011.

15. Vishnubhotla G, Basapogu S, Karnati RKR, Dasari PP, Thommandru MV, Bethu MB. Evaluation of Fluid Absorbency of Retraction Cords after Immersing in Two Retraction Medicaments - An In-vitro Study. Journal of Clinical and Diagnostic Research. JCDR. 2016; 10(11):ZC19-ZC22.

16. Wöstmann B, Rehmann P, Balkenhol M. Influence of different retraction techniques on crevicular fluid flow. Int J Prosthodont. 2008 May-Jun; 21(3):215-6.

Recebido em : 20/05/2017

Aprovado em: 21/06/2017

Os autores declaram que não há conflitos de interesse.

\section{Autor correspondente:}

Mauro de Melo

Rua C254, Qd 579, Lt 12/13, ap 1202, Nova Suíça.

Fones: (62) 3209-6494

CEP. 74280-180 - Goiânia-Goiás

E-mail: mauro@ufg.br / barbaraufg@yahoo.com.br 


\title{
New strategy in the impression technique with tray
}

\begin{abstract}
For the highest quality impressions in Fixed Partial Denture (FPD), a technique was developed of precise and easy application. The tray technique was modified to create the conditions for introducing pressure at the time of insert the impression material. This modification consists in making a hole in the upper acrylic tray, in which the material is injected and has the objective of removing the soft gengival tissues, without retraction cords, which can cause damage to the tissue and / or absorption of fluids that are harmful to the systemic health of certain patients. It is an easy procedure, not traumatic, economical, fast and accurate, making it unnecessary to mechanical removal process.
\end{abstract}

Keywords: Dental Impression Materials; Dental Impression Technique; Dental Marginal Adaptation. 